\title{
Concomitant expression of epithelial-mesenchymal transition biomarkers in breast ductal carcinoma: Association with progression
}

\author{
ÂNGELA FLÁVIA LOGULLO ${ }^{1}$, SUELY NONOGAKI ${ }^{2}$, FÁTIMA SOLANGE PASINI ${ }^{3}$, \\ CYNTHIA APARECIDA BUENO DE TOLEDO OSÓRIO ${ }^{4}$, \\ FERNANDO AUGUSTO SOARES ${ }^{4}$ and M. MITZI BRENTANI ${ }^{3}$
}

\begin{abstract}
${ }^{1}$ Departamento de Patologia, Universidade Federal de São Paulo, São Paulo; ${ }^{2}$ Instituto Adolfo Lutz, Departamento de Patologia; ${ }^{3}$ Disciplina de Oncologia (LIM24), Departamento de Radiologia, da Faculdade de Medicina da USP;

${ }^{4}$ Departamento de Patologia, Hospital A. C. Camargo, São Paulo, Brazil
\end{abstract}

Received July 3, 2009; Accepted August 13, 2009

DOI: $10.3892 /$ or_00000638

\begin{abstract}
Epithelial to mesenchymal transition (EMT) is a process implicated in cancer progression in which the underlying cellular changes have been identified mainly using in vitro models. We determined the expression of some putative EMT biomarkers including E-cadherin, $B$-catenin, zinc finger factor Snail (Snail), transforming growth factor $\beta 1$ (TGFB1), TGFß type II receptor (TBRII) and the HGF receptor (c-met) and their possible correlation to progression and overall survival in a series of breast ductal carcinoma in situ (DCIS) and invasive ductal carcinomas (IDC). Biomarkers were immunohistochemically determined in 55 IDC specimens from which 21 had lymph node metastases and in 95 DCIS specimens, 46 of these cases associated to invasive carcinoma, in a tissue microarray (TMA). Positive cytoplasmic staining of TGFß1 (78.2\%), c-met (43.6\%), Snail (34.5\%), TBRII (100\%), membranous E-cadherin (74.5\%) and membranous/cytoplasmic $\beta$-catenin (71\%) were detected in the IDC samples. Metastatic lymph node samples displayed similar frequencies. A significant increase of c-met and TGFß1 positivity along DCIS to IDC progression was noted but only TGFß1 positivity was associated with presence of lymph node metastases and advanced stages in IDC. The evaluation of the other EMT markers in DCIS did not show differences in positivity rate as compared to invasive carcinomas. DCIS either pure or associated to IDC showed similar expression of the analyzed biomarkers. All the
\end{abstract}

Correspondence to: Dr M.M. Brentani, Disciplina de Oncologia (LIM24), Departamento de Radiologia e Cancerologia, Faculdade de Medicina, Universidade de São Paulo, Av. Dr Arnaldo, 455 sala 4123, CEP 01246-903, São Paulo, SP, Brazil

E-mail: mbrentani@lim24.fm.usp.br

Key words: breast cancer, EMT markers, progression, prognosis carcinomas exhibited positive expression of TBRII. Associations between the markers, determined by Spearman's correlation coefficient, showed a significant association between TGFß1 and respectively E-cadherin, ß-catenin and c-met in DCIS cases, but in invasive carcinomas only cadherin and catenin were positively correlated. Kaplan-Meier survival curves revealed that none of the EMT biomarkers analyzed were correlated with survival, which was significantly determined only by clinical and hormone receptor parameters.

\section{Introduction}

Progression of breast cancer in often accompanied by changes in the pattern of gene expression of neoplastic cells, resulting in a highly tumorigenic and invasive cell phenotype. Some of these changes are reminiscent of an epithelial-mesenchymal transition (EMT), a process characterized by loss of epithelial features and gain of mesenchymal properties (1).

In vitro data suggested that mesenchymal transformation may correlate with loss of epithelial cell adhesion molecules. Reduced expression of E-cadherin is emerging as one of the most common indicators of EMT onset. The disappearance of E-cadherin results in the release of B-catenin and its cytoplasmatic accumulation with further delocalization from the cytoplasm to the nucleus where it can activate LEF/TCF (lymphoid enhancer factor/T cell factor) transcription. In addition, increased production of developmental transcription factors, as Snail, Slug, Twist, FOXC2 and goosecoid, are central mediators of EMT. Snail is a transcription target of twist and it is a repressor of E-cadherin (2). Furthermore, Snail suppresses the expression of claudins and occludins (3). EMT may be triggered by an intricate interplay of extracellular signals including soluble growth factors and members of the TGFß (transforming growth factor $B$ ) family play a critical role as key effectors in cancer progression and metastasis. TGFß1 exerts its effect by binding to the TGFß type II receptor (TBRII), enabling the formation of a complex with type I receptor, resulting in phosphorylation of SMADs which then 
regulate transcription of targets genes repressing E-cadherin and inducing expression of Snail (4). In addition to TGFß, several other tyrosine kinase receptors including c-met play a role in regulating EMT-like morphogenetic events (5). C-met is also induced by TGFß1 (6). Dysregulation was reported of c-met receptor or over-expression of its ligand, the hepatocyte growth factor (HGF) that is produced by stromal cells, has been associated with an aggressive phenotype. Importantly HGF regulates the levels of unbound $\beta$-catenin thus overexpression of c-met may facilitate disruption of E-cadherin junctions (7).

Little is known about the concomitant expression of EMT markers in breast cancer. Since each of the mentioned EMT biomarkers have been considered to be individually important for the malignant behavior of breast cancer we reasoned that the expression of these factors changed with progression and therefore they could be prognostic markers of outcome in breast cancer patients. To this end, the expression of E-cadherin, ß-catenin, Snail, TGFß1 and c-met was immunohistochemically examined in samples of breast carcinoma in situ and in primary invasive tumors. In addition correlations among the expression of this EMT markers were evaluated in both DCIS and IDC the potential prognostic value of each EMT marker expression was assessed.

\section{Materials and methods}

Breast tumor samples and patient data. Formalin-fixed and paraffin-embedded tissue specimens from a total of 55 patients diagnosed with invasive ductal breast carcinoma (IDC) at the A.C. Camargo Cancer Hospital, São Paulo, Brazil, between 1993 and 2005 were included in this study after approval by its Institutional review board and was referred as the experimental set of tumors. In addition, tissue microarrays containing 95 cases of ductal carcinoma in situ (DCIS), 50 of these cases associated to invasive carcinoma, diagnosed at the Department of Pathology Cancer from 1980-2001, were produced. All DCIS tumor samples were also ductal carcinomas. All cases were reviewed by A.F.L., C.T.O. and F.A.S. to corroborate the diagnosis. Characteristics of these retrospective cohorts are detailed in Table I. Patients were enrolled according to the inclusion criteria consisting of suitable paraffin blocks for immunohistochemistry, adequate clinical parameters and follow-up information. None of the patients with pure DCIS had experienced recurrence or progression to an invasive cancer within the median followup time. Histologic typing and grade for invasive cases were defined according to the WHO and modified Scarf-BloomRichardson classifications. DCIS nuclear grade was estimated using the Lagios classification.

Construction of tissue microarrays (TMAs). TMAs were constructed from 1.50-mm cores of formalin-fixed, paraffinembedded archival tissue specimens using a tissue arraying instrument (Beecher Instruments) as previously described by us (8). TMAs were then sectioned $(4 \mu \mathrm{M})$ and mounted on positively charged glass slides for immunohistochemistry (IHC) analysis. The presence of tumor tissue in each core was confirmed by H\&E staining of TMA slides.
Table I. Data of ductal breast carcinoma patients.

\begin{tabular}{lcc}
\hline Characteristics & $\begin{array}{c}\text { Invasive } \\
(\mathrm{n}=55)\end{array}$ & $\begin{array}{c}\text { In situ } \\
(\mathrm{n}=95)\end{array}$ \\
\hline Median age (range) & $56(33-80)$ & \\
Histology & & \\
Comedo & & $7(7.4)$ \\
Non-comedo & & $88(92.6)$ \\
N stage & & \\
N0 & & \\
N+ & $20(36.4)$ & \\
T stage & $35(63.6)$ & \\
T1 + T2 & & \\
T3 + T4 & $43(78.2)$ & \\
Disease stage & $12(21.8)$ & \\
TxN0M0 & & \\
TxN1M0 & $16(29.1)$ & \\
TxN2M0 & $15(27.3)$ & \\
TxNxM1 & $8(14.5)$ & \\
Estrogen receptors (n=42) & $16(29.1)$ & \\
Positive & & \\
Negative & & \\
Progesterone receptors $(\mathrm{n}=42)$ & & \\
Positive & & \\
Negative & & \\
Differentiation & & \\
Well & & \\
Moderate & & \\
Poor & & \\
Status & & \\
Alive & & \\
Deceased & & \\
\hline
\end{tabular}

Immunohistochemistry. Monoclonal antibodies to ß-catenin, E-cadherin, c-met and TGFß1 were obtained from Novocastra (Newcastle, UK) and diluted 1:100, 1:50, 1:50 and 1:25, respectively. TBRII (polyclonal ready for use), Snai-1 and c-met were purchased from Santa Cruz Biotechnology (Santa Cruz, CA, USA) and diluted 1:100. Each slide was also stained with anti-ER (Neomarkers, clone 6F-11, 1:50) and anti-PR (Dako, clone PgR636, 1:500).

After deparaffinazation and rehydration of sections or tissue microarrays from formalin-fixed paraffin-embedded samples, antigen retrieval was performed in a pressure cooker. Endogenous peroxidase activity was blocked with $3 \% \mathrm{H}_{2} \mathrm{O}_{2}$. Incubation with primary antibody was performed overnight at $4^{\circ} \mathrm{C}$. Slides were incubated with biotinylated goat antimouse/rabbit Ig, or biotinylated rabbit anti-goat Ig (for SNAI 1) followed by streptABC/HRP (Dako, Denmark). Slides were developed by diaminobenzidine (Sigma, USA) and $6 \% \mathrm{H}_{2} \mathrm{O}_{2}$ 
Table II. Comparison of protein expression markers between in situ and invasive ductal breast carcinoma.

\begin{tabular}{|c|c|c|c|c|}
\hline \multirow[b]{2}{*}{ Protein expression } & \multicolumn{2}{|c|}{ In situ $(\%)$} & \multirow[b]{2}{*}{ Invasive $(\%)$} & \multirow[b]{2}{*}{ P-value } \\
\hline & Pure & With invasive component & & \\
\hline \multicolumn{5}{|l|}{ TGFß1 } \\
\hline Negative & $23(46.9)$ & $26(56.5)$ & $12(21.8)$ & 0.001 \\
\hline Positive & $26(53.1)$ & $20(43.5)$ & $43(78.2)$ & \\
\hline \multicolumn{5}{|l|}{ E-cadherin } \\
\hline Negative & $9(18.4)$ & $10(21.7)$ & $14(25.5)$ & 0.68 \\
\hline Positive & $40(81.6)$ & $36(78.3)$ & $41(74.5)$ & \\
\hline \multicolumn{5}{|l|}{ ß-catenin } \\
\hline Negative & $14(28.6)$ & $18(39.1)$ & $16(29.1)$ & 0.46 \\
\hline Positive & $35(71.4)$ & $28(60.9)$ & $39(70.9)$ & \\
\hline \multicolumn{5}{|l|}{ Snail } \\
\hline Negative & $34(70.8)$ & $36(78.3)$ & $36(65.5)$ & 0.37 \\
\hline Positive & $14(29.2)$ & $10(21.7)$ & $19(34.5)$ & \\
\hline \multicolumn{5}{|l|}{ c-Met } \\
\hline Negative & $45(91.8)$ & $40(87.0)$ & $31(56.4)$ & $<0.001$ \\
\hline Positive & $4(8.2)$ & $6(13.0)$ & $24(43.6)$ & \\
\hline
\end{tabular}

Expression: negative, no expression to + ; positive, ++ to +++ ; excepting for $\beta$-catenin were negative, no expression and positive, + to +++ . $\mathrm{P}$, statistical significance by $\chi^{2}$ test.

and counterstained with Harris hematoxylin. Negative controls were performed by omission of the respective primary antibody. Sections from tissues previously recognized as positive for the selected antibodies were used positive controls. Evaluation of immunostaining scoring was performed by light microscopy. Expression of the biomarkers was semiquantiatatively analyzed by two of the pathologists (A.F.L. and F.A.S.). Specimens that exhibited a complete absence of staining or $\leq 10 \%$ of positive cells were considered as negative. Slides were scored according to the percentage of cells showing positivity: $10-25 \%,+; 25-50 \%,++$; and $>50 \%$, +++ . For practical and statistical purposes we grouped the cases presenting $10-25 \%$ of positive cells (weakly positive) with the negative cases. Cases graded as moderately (++) and strongly positive $(+++)$ were considered as positive tumors.

Statistical methods. The Spearman's rho pairwise bivariate correlations test was used to estimate the relationship between staining patterns of the different antibodies used. Correlation between antigen expression and other clinicopathological parameters was studied by the $\chi^{2}$ test. Survival probabilities were estimated by the univariate Kaplan-Meier method, survival curves were compared by the log-rank (MantelHaenszel method). P-values $<0.05$ were considered to be statistically significant. Analysis was performed with SPSS for Windows (release 10.0; SPSS Inc., Chicago, IL, USA).

\section{Results}

Table II summarizes protein expression results in in situ or in invasive breast ductal carcinoma. Immunohistochemical analysis revealed TGFß1 in $78.2 \%$ of the invasive cases and the staining was localized in the cytoplasm of tumor cells. ß-catenin displaying membranous and or cytoplasmic staining was observed in $70.9 \%$ of the cases and was not found in the nucleus. Membranous E-cadherin staining was positive in $74.5 \%$ of cases but complete loss was recorded in only 5 cases, c-met and Snail were expressed in respectively 43.6 and $34.5 \%$ of invasive breast cancer samples irrespective of nodal involvement and the staining pattern with both antibodies was cytoplasmic (Fig. 1). Most of the positive cases demonstrated a moderate staining for Snail. The evaluation of E-cadherin and Snail expression did not show significant differences in percentage of positivity in DCIS cases as compared to invasive carcinomas. On the other hand, we noted a highly significant increase in positivity of TGFß1 and in c-met expression along DCIS to IDC progression (53.1 and $8.2 \%$ in DCIS versus 78.2 and $43.6 \%$, respectively). B-catenin staining was predominantly membranous in DCIS whereas the staining pattern of the other markers was the same as that seen in the invasive carcinomas. All in situ and invasive carcinomas exhibited positive expression of TBRII (Fig. 2). DCIS either pure or associated to invasive carcinoma did not show differences in frequency of expression of the analyzed biomarkers.

Our next step was to analyze the possible correlation between expression of the different EMT markers in either DCIS or in IDC cases (Table III). In invasive carcinomas no significant correlation between all studied markers was observed except for a strong association between E-cadherin and $\beta$-catenin $(\mathrm{P}=0.007)$. On the other hand in DCIS cases, significant positive association between TGFß1 and 

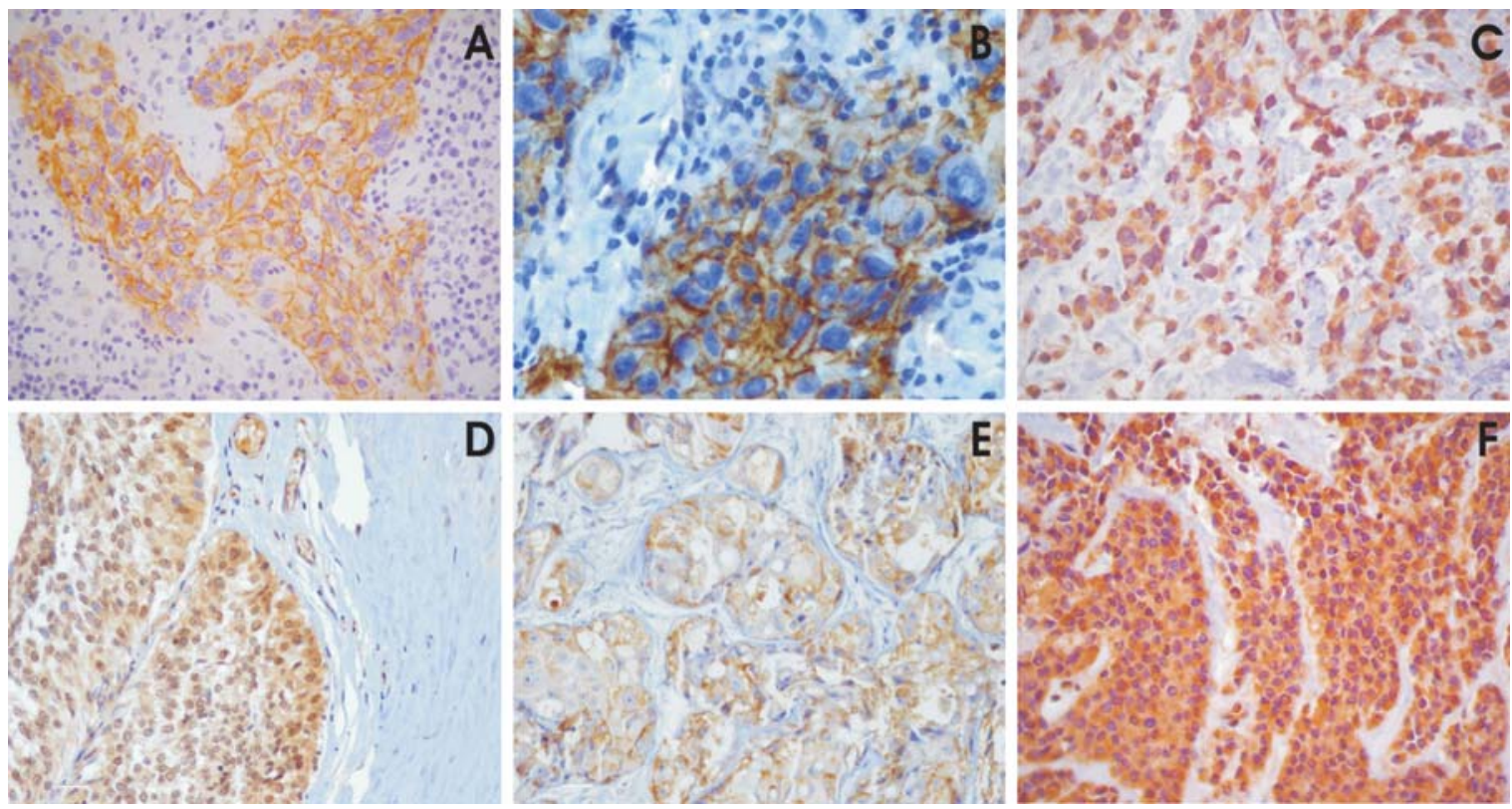

Figure 1. Immunohistochemical detection of EMT proteins in primary breast ductal invasive carcinoma (IDC). (A) Preserved membrane immunoreactivity for E-cadherin (x40) and (B) B-catenin (x100); note a redistribution of B-catenin to the cytoplasm at the interface of the invasion front. (C) Diffuse cytoplasmic staining of TGFß1 (x40) and (D) TBRII (x40); (E) granular and cytoplasmatic pattern of Snail (x200) and (F) c-met.
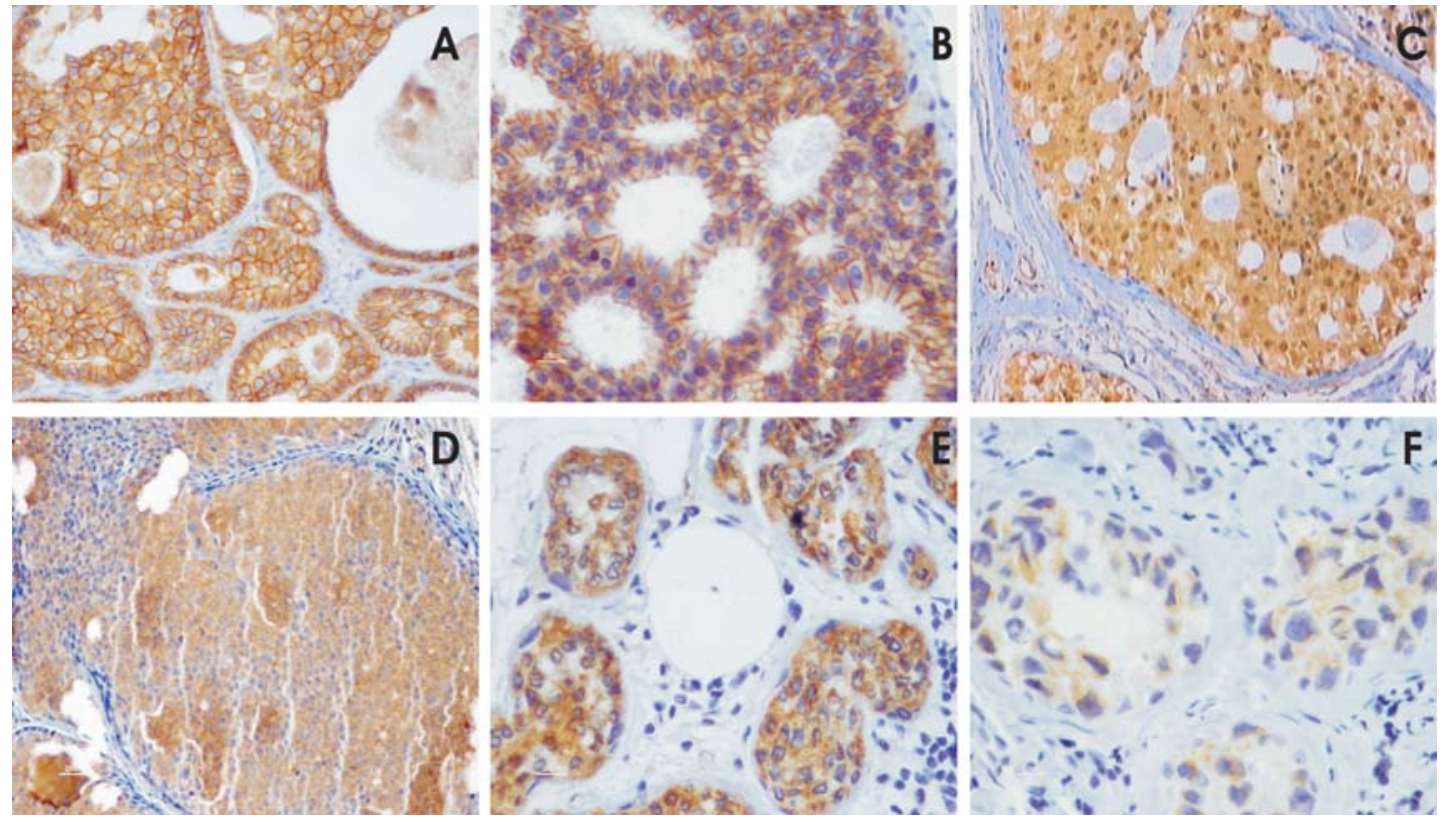

Figure 2. Immunohistochemical detection of EMT proteins in breast ductal carcinoma in situ (DCIS). (A) Preserved membrane staining for E-cadherin (x40); (B) B-catenin (x100); (C) Diffuse cytoplasmic staining of TGFß1 (x40) and (D) TBRII (x200); (E) granular and subtle cytoplasmatic pattern of Snail (x200) and (F) c-met (x200).

respectively E-cadherin $(\mathrm{P}=0.001), \beta$-catenin $(\mathrm{P}=0.004)$ and c-met $(\mathrm{P}=0.035)$ were noted.

The prognostic value of all proteins was evaluated by comparing the expression of each EMT marker to classical prognostic variables (presence of metastasis, histological differentiation and immunohistochemical estrogen and progesterone receptor status). TGFß1 positive cases were associated with advanced stage and presence of compromised lymph nodes (Table IV). No correlation was found between any EMT protein expression and clinicopathological features of the cases.

In DCIS, no correlation was found between EMT protein expression and tumor histology, presence of ER or PR or differentiation status. In 21 invasive carcinoma cases, samples of the metastatic lymph nodes were obtained. The expression of EMT markers in lymph nodes and in the matched primary tumors was compared and a similar frequency of all biomarkers was observed (Table V). 
Table III. Relationship between tumor marker expression in ductal breast carcinoma.

\begin{tabular}{|c|c|c|c|c|}
\hline Variable & E-Cadherin & B-catenin & Snail & c-Met \\
\hline \multicolumn{5}{|l|}{ In situ } \\
\hline \multicolumn{5}{|l|}{ TGFß1 } \\
\hline Spearman correlation & 0.326 & 0.289 & 0.123 & 0.217 \\
\hline P-value & 0.001 & 0.004 & 0.239 & 0.035 \\
\hline \multicolumn{5}{|l|}{ E-cadherin } \\
\hline Spearman correlation & & 0.089 & 0.173 & 0.171 \\
\hline P-value & & 0.391 & 0.095 & 0.097 \\
\hline \multicolumn{5}{|l|}{ ß-catenin } \\
\hline Spearman correlation & & & 0.158 & 0.169 \\
\hline P-value & & & 0.126 & 0.100 \\
\hline \multicolumn{5}{|l|}{ Snail } \\
\hline Spearman correlation & & & & 0.037 \\
\hline P-value & & & & 0.719 \\
\hline \multicolumn{5}{|l|}{ Invasive } \\
\hline \multicolumn{5}{|l|}{ TGFß1 } \\
\hline Spearman correlation & 0.096 & -0.048 & -0.079 & -0.68 \\
\hline P-value & 0.488 & 0.730 & 0.566 & 0.623 \\
\hline \multicolumn{5}{|l|}{ E-cadherin } \\
\hline Spearman correlation & & 0.361 & -0.014 & 0.178 \\
\hline P-value & & 0.007 & 0.917 & 0.195 \\
\hline \multicolumn{5}{|l|}{ ß-catenin } \\
\hline Spearman correlation & & & 0.044 & 0.160 \\
\hline P-value & & & 0.748 & 0.243 \\
\hline \multicolumn{5}{|l|}{ Snail } \\
\hline Spearman correlation & & & & -0.022 \\
\hline P-value & & & & 0.871 \\
\hline
\end{tabular}

Spearman's rho test. A two-sided P-value $<0.05$ was considered statistically significant.

To determine whether the expression of each of the proposed EMT markers may affect the survival of the patients we prepared Kaplan-Meier survival curves and analyzed them by the log-rank test. Because several clinical parameters are known to affect survival we also analyzed clinical parameters. Survival was found to be reduced in patients presenting compromised lymph nodes $(\mathrm{P}=0.018)$ with moderate/poor differentiated $(\mathrm{P}=0.001)$ or with negative receptors $(\mathrm{P}<0.001)$. However, none of the analyzed EMT markers showed a significant correlation with survival.

\section{Discussion}

In this study the expression of several markers associated with the EMT phenotype was concomitantly analyzed in a well defined cohort of breast tumors diagnosed as ductal carcinomas. We sought to document whether the expression of these factors changed with progression of breast carcinoma and to analyze their utility as biomarkers for overall survival of invasive ductal breast carcinoma patients.

Among the EMT markers evaluated, we observed an increased proportion of c-met and TGFß1 positivity along the DCIS to invasive ductal breast cancer suggesting their association with tumor progression.

Positivity rate of c-met in invasive and in situ breast carcinoma was in the range of two previous studies using immunohistochemistry $(9,10)$. We did not find c-met expression useful in predicting overall survival, although a correlation between c-met and adverse outcome has been reported (10). In this aforementioned study the authors focused on total c-met expression (cytoplasmic and membrane staining) and in our cases we observed only cytoplasmic staining. As we did not find differences in TGFß1 positivity between pure in situ cases and those associated 
Table IV. Correlation of TGFß1 expression in invasive ductal breast carcinoma with other prognostic factors.

\begin{tabular}{|c|c|c|c|}
\hline \multirow[b]{2}{*}{ Characteristics } & \multicolumn{2}{|c|}{ TGFß1 expression } & \multirow[b]{2}{*}{ P-value } \\
\hline & Negative $(\%)$ & Positive (\%) & \\
\hline \multicolumn{4}{|l|}{$\mathrm{N}$ stage } \\
\hline No & $8(66.7)$ & $12(27.9)$ & 0.018 \\
\hline $\mathrm{N}+$ & $4(33.34)$ & $31(72.1)$ & \\
\hline \multicolumn{4}{|l|}{ T stage } \\
\hline $\mathrm{T} 1+\mathrm{T} 2$ & $9(81.8)$ & $34(79.0)$ & 1.00 \\
\hline $\mathrm{T} 3+\mathrm{T} 4$ & $2(18.2)$ & $9(21.0)$ & \\
\hline \multicolumn{4}{|l|}{ M stage } \\
\hline M0 & $12(100.0)$ & $27(62.8)$ & 0.012 \\
\hline M1 & $0(0)$ & $16(37.2)$ & \\
\hline \multicolumn{4}{|l|}{ Differentiation } \\
\hline Well & $3(25.0)$ & $11(25.6)$ & 0.10 \\
\hline Moderate & $2(16.7)$ & $20(46.5)$ & \\
\hline Poor & $7(58.3)$ & $12(26.9)$ & \\
\hline \multicolumn{4}{|c|}{ Estrogen receptors } \\
\hline Positive & $4(57.1)$ & $23(65.7)$ & 0.68 \\
\hline Negative & $3(42.9)$ & $12(34.3)$ & \\
\hline \multicolumn{4}{|c|}{ Progesterone receptors } \\
\hline Positive & $5(71.4)$ & $18(51.4)$ & 0.43 \\
\hline Negative & $2(28.6)$ & $17(48.6)$ & \\
\hline
\end{tabular}

to invasive tumors it appears that TGFß1 status is not a predictor of the clinical course of DCIS in our series. Although our results suggested an association between TGFß1 and aggressive tumor phenotype (compromised lymph node and advanced stages), implying that an increased TGFß1 production by tumor cells may augment certain aspects of their malignant phenotype, no relationship with overall survival was found. An elevated expression of TGFß1 in invasive breast cancer was reported to be associated with disease progression in some studies whereas, others did not describe this predictive values (reviewed in ref. 11). Different methodologies of TGFß1 evaluation may in part explain different results. Alternatively TGFß1 may affect survival indirectly, by inducing the expression of other cytokines that confers metastatic ability as recently suggested (12) explaining perhaps the conflicting results of a number of studies engaged to evaluate the potential prognostic value of TGFß1. Oncogenic properties of TGFß1 seem to involve loss of TGFß1 receptor proteins (13) but again TBRII expression was retained in our cases. However, we can not discard the possibility of alterations in the SMAD signal transducers or activation of non-SMAD signaling pathways by TGFß1 (4).
Table V. Comparison of protein expression markers between primary invasive ductal breast carcinoma and lymph node metastases.

Protein expression Invasive (\%) Lymph node (\%) P-value

\begin{tabular}{lrrr}
\hline TGFß1 & & & \\
Negative & $2(14.3)$ & $2(14.3)$ & 1.00 \\
Positive & $12(87.7)$ & $12(87.7)$ & \\
E-cadherin & & & \\
Negative & $7(33.3)$ & $3(14.3)$ & 0.28 \\
Positive & $14(66.7)$ & $18(85.7)$ & \\
ß-catenin & & & \\
Negative & $6(28.6)$ & $11(52.7)$ & 0.20 \\
Positive & $15(69.7)$ & $10(47.6)$ & \\
Snail & & & \\
Negative & $17(85.0)$ & $18(90.0)$ & 1.00 \\
Positive & $3(15.0)$ & $2(10.0)$ & \\
c-Met & & & \\
Negative & $10(76.9)$ & $8(61.5)$ & 1.00 \\
Positive & $3(23.1)$ & $5(38.5)$ & \\
\hline
\end{tabular}

Expression: negative, no expression to + ; positive, ++ to +++ ; Fisher's exact paired test. A two-sided P-value $<0.05$ was considered statistically significant.

In accordance to several previous reports we found that E-cadherin expression (membrane linked) was preserved in a considerable proportion of invasive breast cancer, and a similar frequency was displayed by in situ tumors (14-20). We did not show that E-cadherin deficiency is a prognostic determinant for survival in agreement with some studies but in contrast to others (21). In spite of being considered as a transcriptional repressor of E-cadherin we failed to verify an indirect relationship between Snail and E-cadherin in ductal breast carcinomas as demonstrated by recent data analyzing Snail messenger RNAs (22). Because of the low repression capacity of Snail on this promotor, it was suggested that other cell specific correpressors are need for complete shutdown of the E-cadherin transcription (23). It was suggested that a function of Snail is to provide cells with survival properties (24) but, we did not find any association between Snail and poor prognostic factors conflicting with few previous studies that reported an association between Snail and presence of metastasis $(24,25)$.

In the present study, $\beta$-catenin staining pattern was predominantly membranous in DCIS whereas in the central parts of invasive breast carcinoma it was also localized in the membrane and cytoplasm and absent in the nucleus consistent with other studies $(15,16,26-30)$. However, at the invasive front, in advanced tumors, we have observed a loss of plasma membrane $\beta$-catenin accompanied by cytoplasmic accumulation, suggesting that specific signals from the tumor environment may regulate locally the intracellular $\beta$-catenin distribution. We chose to evaluate the total level of $B$ catenin expression as the sum of membrane and cytoplasmic 
staining as described previously (27), but we did not find a correlation between reduction in immunoreactivity of ß-catenin and poor prognostic markers, a result aligned with several authors, but in disagreement with others. Discrepant results in the literature, reviewed by Dolled-Filhart et al (28), might be due to the lack of detailed information considering different localizations of $\beta$-catenin and emphasizing the necessity of analysis of total tumors sections.

In summary, when analyzing the individual prognostic value of the proposed EMT markers in the present study, in comparison with results of other groups, we observed a large variability arising from heterogeneity and size of the cohorts, nature of the antibodies selected, distinct scoring systems and detection methods.

The expected association among EMT was not found in IDC suggesting that in vivo, the expression level of each variable in a given tumor assessed as part of the EMT phenotype is a result of specific complex regulatory pathways. Only an association between E-cadherin and B-catenin was observed indicating that perhaps the sustained E-cadherin/ B-catenin axis might be important for disease progression in this particular type of breast carcinoma (16). Statistical coexpression of some different EMT markers that were found in DCIS (such as c-met versus TGFß1), but disappears in IDC, suggested that such markers may have different functions during tumor progression.

Axillary lymph node metastasis is considered an important event in the metastatic process of breast cancer. We verified that the EMT signature analyzed in the present study could not distinguish the metastatic samples from primary tumors. For instance we found that lymph node metastases continue to express E-cadherin, B-catenin and c-met in accordance with previous studies (31-33), suggesting that the gene expression profiles displayed by primary breast carcinomas and by matching lymph nodes are highly alike (34).

In conclusion, none of the EMT biomarkers analyzed by immunohistochemistry in the present study showed significant prognostic value whereas the prognosis was significantly determined by clinical and hormone parameters.

\section{Acknowledgements}

This study was supported by FAPESP no. 04/04607-8 and CNPq.

\section{References}

1. Thiery JP: Epithelial-mesenchymal transitions in tumour progression. Nat Rev Cancer 2: 442-454, 2002.

2. Lee JM, Dedhar S, Kalluri R and Thompson EW: The epithelialmesenchymal transition: new insights in signaling, development, and disease. J Cell Biol 172: 973-981, 2006.

3. Ikenouchi J, Matsuda M, Furuse M and Tsukita S: Regulation of tight junctions during the epithelium-mesenchyme transition: direct repression of the gene expression of claudins/occludin by Snail. J Cell Sci 116: 1959-1967, 2003.

4. Xu J, Lamouille S and Derynck R: TGF-beta-induced epithelial to mesenchymal transition. Cell Res 19: 156-172, 2009.

5. Birchmeier C, Birchmeier W, Gherardi E and Vande Woude GF: Met, metastasis, motility and more. Nat Rev Mol Cell Biol 4 915-925, 2003

6. Murai M, Shen X, Huang L, Carpenter WM, Lin CS, Silverman S, Regezi J and Kramer RH: Overexpression of c-met in oral SCC promotes hepatocyte growth factor-induced disruption of cadherin junctions and invasion. Int J Oncol 25: 831-840, 2004.
7. Zhang X, Yang J, Li Y and Liu Y: Both Sp1 and Smad participate in mediating TGF-beta1-induced HGF receptor expression in renal epithelial cells. Am J Physiol Renal Physiol 288: F16-F26, 2005.

8. Mangone FR, Brentani MM, Nonogaki S, Begnami MD, Campos AH, Walder F, Carvalho MB, Soares FA, Torloni $\mathrm{H}$, Kowalski LP and Federico MH: Overexpression of Fos-related antigen-1 in head and neck squamous cell carcinoma. Int $\mathrm{J}$ Exp Pathol 86: 205-212, 2005.

9. Lindemann K, Resau J, Nährig J, Kort E, Leeser B, Annecke K, Welk A, Schäfer J, Vande Woude GF, Lengyel E and Harbeck N: Differential expression of c-Met, its ligand HGF/SF and HER2/ neu in DCIS and adjacent normal breast tissue. Histopathology 51: 54-62, 2007.

10. Lengyel E, Prechtel D, Resau JH, Gauger K, Welk A, Lindemann K, Salanti G, Richter T, Knudsen B, Vande Woude GF and Harbeck N: C-Met overexpression in node-positive breast cancer identifies patients with poor clinical outcome independent of Her2/neu. Int J Cancer 113: 678-682, 2005.

11. Desruisseau S, Palmari J, Giusti C, Romain S, Martin PM and Berthois Y: Determination of TGFbeta1 protein level in human primary breast cancers and its relationship with survival. Br J Cancer 94: 239-246, 2006.

12. Gobbi H, Arteaga CL, Jensen RA, Simpson JF, Dupont WD, Olson SJ, Schuyler PA, Plummer WD Jr and Page DL: Loss of expression of transforming growth factor beta type II receptor correlates with high tumour grade in human breast in-situ and invasive carcinomas. Histopathology 36: 168-177, 2000.

13. Padua D, Zhang XH, Wang Q, Nadal C, Gerald WL, Gomis RR and Massagué J: TGFbeta primes breast tumors for lung metastasis seeding through angiopoietin-like 4. Cell 133: 66-77, 2008.

14. Bukholm IK, Nesland JM, Kåresen R, Jacobsen U and Børresen-Dale AL: E-cadherin and alpha-, beta-, and gammacatenin protein expression in relation to metastasis in human breast carcinoma. J Pathol 185: 262-266, 1998.

15. Bànkfalvi A, Terpe HJ, Breukelmann D, Bier B, Rempe D, Pschadka G, Krech R, Lellè RJ and Boecker W: Immunophenotypic and prognostic analysis of E-cadherin and beta-catenin expression during breast carcinogenesis and tumour progression: a comparative study with CD44. Histopathology 34: 25-34, 1999.

16. Gillett CE, Miles DW, Ryder K, Skilton D, Liebman RD, Springall RJ, Barnes DM and Hanby AM: Retention of the expression of E-cadherin and catenins is associated with shorter survival in grade III ductal carcinoma of the breast. J Pathol 193: 433-441, 2001

17. Acs G, Lawton TJ, Rebbeck TR, LiVolsi VA and Zhang PJ: Differential expression of E-cadherin in lobular and ductal neoplasms of the breast and its biologic and diagnostic implications. Am J Clin Pathol: 85-98, 2001.

18. Rakha EA, Abd El Rehim D, Pinder SE, Lewis SA and Ellis IO E-cadherin expression in invasive non-lobular carcinoma of the breast and its prognostic significance. Histopathology 46: 685-693, 2005

19. Qureshi HS, Linden MD, Divine G and Raju UB: E-cadherin status in breast cancer correlates with histologic type but does not correlate with established prognostic parameters. Am J Clin Pathol 125: 377-385, 2006.

20. Mahler-Araujo B, Savage K, Parry S and Reis-Filho JS: Reduction of E-cadherin expression is associated with non-lobular breast carcinomas of basal-like and triple negative phenotype. J Clin Pathol 61: 615-620, 2007.

21. Gould Rothberg BE and Bracken MB: E-cadherin immunohistochemical expression as a prognostic factor in infiltrating ductal carcinoma of the breast: a systematic review and metaanalysis. Breast Cancer Res Treat 100: 139-148, 2006.

22. Côme C, Magnino F, Bibeau F, De Santa Barbara P, Becker KF, Theillet $C$ and Savagner P: Snail and slug play distinct roles during breast carcinoma progression. Clin Cancer Res 12: 5395-5402, 2006.

23. De Craene B, Gilbert B, Stove C, Bruyneel E, van Roy F and Berx G: The transcription factor snail induces tumor cell invasion through modulation of the epithelial cell differentiation program. Cancer Res 65: 6237-6244, 2005.

24. Barrallo-Gimeno A and Nieto MA:The Snail genes as inducers of cell movement and survival: implications in development and cancer. Development 132: 3151-3161, 2005.

25. Blanco MJ, Moreno-Bueno G, Sarrio D, Locascio A, Cano A, Palacios J and Nieto MA: Correlation of Snail expression with histological grade and lymph node status in breast carcinomas. Oncogene 21: 3241-3246, 2002. 
26. Karayiannakis AJ, Nakopoulou L, Gakiopoulou H, Keramopoulos A, Davaris PS and Pignatelli M: Expression patterns of beta-catenin in situ and invasive breast cancer. Eur J Surg Oncol 27: 31-36, 2001 .

27. Chung GG, Zerkowski MP, Ocal IT, Dolled-Filhart M, Kang JY, Psyrri A, Camp RL and Rimm DL: beta-Catenin and p53 analyses of a breast carcinoma tissue microarray. Cancer 100: 2084-2092, 2004

28. Dolled-Filhart M, McCabe A, Giltnane J, Cregger M, Camp RL and Rimm DL: Quantitative in situ analysis of beta-catenin expression in breast cancer shows decreased expression is associated with poor outcome. Cancer Res 66: 5487-5494, 2006.

29. Nakopoulou L, Mylona E, Papadaki I, Kavantzas N, Giannopoulou I, Markaki S and Keramopoulos A: Study of phospho-beta-catenin subcellular distribution in invasive breast carcinomas in relation to their phenotype and the clinical outcome. Mod Pathol 19: 556-563, 2006.

30. Toya H, Oyama T, Ohwada S, Togo N, Sakamoto I, Horiguchi J Koibuchi Y, Adachi S, Jigami T, Nakajima T and Akiyama T: Immunohistochemical expression of the beta-catenin-interacting protein B9L is associated with histological high nuclear grade and immunohistochemical ErbB2/HER-2 expression in breast cancers. Cancer Sci 98: 484-490, 2007.
31. Bukholm IK, Nesland JM and Børresen-Dale AL: Re-expression of E-cadherin, alpha-catenin and beta-catenin, but not of gammacatenin, in metastatic tissue from breast cancer patients. J Pathol 190: 15-19, 2000.

32. Kowalski PJ, Rubin MA and Kleer CG: E-cadherin expression in primary carcinomas of the breast and its distant metastases. Breast Cancer Res 5: R217-R222, 2003.

33. Beviglia L, Matsumoto K, Lin CS, Ziober BL and Kramer RH: Expression of the c-Met/HGF receptor in human breast carcinoma: correlation with tumor progression. Int J Cancer 74: 301-309, 1997.

34. Ma XJ, Salunga R, Tuggle JT, Gaudet J, Enright E, McQuary P, Payette T, Pistone M, Stecker K, Zhang BM, Zhou YX, Varnholt H, Smith B, Gadd M, Chatfield E, Kessler J, Baer TM, Erlander MG and Sgroi DC: Gene expression profiles of human breast cancer progression. Proc Natl Acad Sci USA 100: 5974-5979, 2003. 